\title{
Colloquium Humanarum
}

\section{APRESENTAÇÃO}

A Educação Infantil brasileira é uma 'jovem' área; sua história é relativamente curta, se consideramos que o atendimento educacional formal para as crianças pequenas e bebês (pré-escola e creche) só foi legalmente incluído/reconhecido como etapa da educação básica com a Lei de Diretrizes e Bases da Educação Nacional $n^{\circ}$. 9.394 de 1996. Neste bojo, as ações educativas, por todo o país, mesmo com diretrizes legais instituídas e certo avanço de discussões acadêmicas, ainda se caracterizam por uma miscelânea de concepções e práticas que nem sempre concretizam o que se espera como ideal para esse nível de ensino.

Dessa forma, não é descuidado trazer à tona a afirmação de que a Educação Infantil ainda é um campo (no sentido bordieusiano da palavra) em construção, como também de disputas em busca de consolidação de sua identidade específica. Tal contexto também nos permite crer que é sempre oportuno refletir sobre o que queremos e como esperamos que seja, na prática, a educação formal das crianças que frequentam essa etapa educacional.

Imbuídos destas premissas e em tempo de amplas, necessárias e acirradas discussões sobre a educação, a função da escola, o papel do professor e o currículo escolar é que organizamos e ora apresentamos aos leitores da Revista Colloquium Humanarum o dossiê "Educação Infantil: formação de professores, currículo e práticas".

O coletivo de autores aqui reunido oferece a possibilidade de pensar sobre a infância e os processos educativos sob diferentes perspectivas teóricas. As temáticas abordadas em artigos resultantes de pesquisas e experiências de ensino sinalizam a urgência de tratarmos questões que se voltam para as políticas públicas, a formação dos professores - em diferentes níveis - e as práticas pedagógicas para a Educação Infantil.

Os textos, provenientes de diferentes espaços, nacionais e internacionais, mostram a preocupação dos autores em promover o debate com vistas à superação de compreensões equivocadas tais como: a da infância como um momento apenas de passagem; da criança como um vir-a-ser; a instituição de educação infantil como assistencialista e de cuidados das necessidades físicas; bem como que profissionais para atuarem junto às crianças pequenas não precisam de formação específica, mas sendo requisito gostar delas e ser mulher...

Temos então, abrindo a sessão de artigos do dossiê, o texto dos pesquisadores portugueses Amélia Marchão e Helder Henriques, intitulado: "Entre a investigação-ação, a supervisão e a reflexão na formação inicial de educadores de infância no Portugal de hoje" que discute a formação inicial de educadores de infância sob a vigência da legislação mais atual em Portugal. Os autores focam os processos de estágio e o modo como estes são desenvolvidos no contexto português, apontando a investigação-ação como possibilidade de modelo e as práticas de supervisão numa perspectiva de questionamento crítico. 
Apontam, a partir da revisão de literatura, das suas experiências e revisitação às vozes de estudantes envolvidas em dois estudos, a importância dos canais de comunicação entre a instituição de formação e os locais de estágio; os aspectos a serem considerados no processo de estágio/investigação-ação e a importância de uma supervisão que promova o pensamento crítico dos estudantes.

Em seguida, temos o artigo "A formação docente na Educação Infantil: levantamentos de nuances", assinado por Jany Rodrigues Prado, Regivane dos Santos Brito e Cláudio Pinto Nunes, apresentando resultados do estudo que buscou analisar os sentidos que os professores da Educação Infantil da rede municipal de Guanambi-BA atribuem a sua formação. A análise aponta que, nos últimos anos, foram criadas importantes políticas rumo à educação de qualidade para as crianças pequenas; entretanto, existem ainda muitos enfrentamentos que envolvem a educação infantil.

Abordando a política instituída pelo Ministério da Educação que propõe a (re)formulação curricular a partir de uma Base Nacional Comum Curricular, Rejane Neto Costa, Anelise Monteiro do Nascimento e Luana Ramos Neves apresentam o texto "Base Nacional Comum Curricular: implementação da proposta curricular para a Educação Infantil no município de Nova Iguaçu". As autoras tratam especificamente das proposições dessa política para o segmento da Educação Infantil e seus desdobramentos em nível municipal, explicitando o acompanhamento realizado nos anos de 2018 e 2019 do trabalho organizado pela Secretaria Municipal de Educação do município de Nova Iguaçu.

Luiz Martins Junior, Julice Dias e Rosa Elisabete Militz Wypyczynski Martins, autores do texto "Em nome da tradição: a relação escola-cidade-famílias no cotidiano da (pré)-escola", trazem dados obtidos na pesquisa que investigou a relação de mães com uma escola confessional católica blumenauense, referência no cenário local. A análise evidencia que as inovações ou alterações curriculares não foram resultantes da interação escola e famílias; mas, de pressões externas, oriundas de discursos hegemônicos veiculados pelo modismo pedagógico da época. Os autores acreditam que pelo fato de a escola ser referência no município, não poderia deixar de estar à altura das demandas sociais e pedagógicas que os tempos da redemocratização do país e da profusão da sociedade do conhecimento exigiam dos processos escolares.

Discutir a formação inicial e continuada de professores e profissionais da área da Educação Infantil é o foco do artigo intitulado "NDI comunidade: ampliando a relação teoria e prática na formação inicial e continuada de acadêmicos e profissionais da Educação Infantil”, de autoria de Carolina S. Spinelli, Juliana Euzébio e Juliete Schneider. A discussão apresentada gira em torno das atividades do projeto de Extensão NDI Comunidade, desenvolvido pela Universidade Federal de Santa Catarina, que articula ensino e pesquisa ao estabelecer o diálogo entre as práticas pedagógicas e as pesquisas realizadas pelos seus professores. No texto, os autores apresentam o projeto, suas ações e sua amplitude na formação inicial e continuada de professores para a Educação Infantil, a partir da análise da avaliação dos participantes ao longo de um ano e meio de realização do projeto.

O texto seguinte, de autoria de Larissa Aparecida Trindade e Célia Maria Guimarães, tem como título: "O ato educativo na Educação Infantil sob a ótica da pedagogia histórico-crítica", e discute o 
processo de formação continuada de uma professora pré-escolar ocorrido por meio de intervenções teóricas e práticas, com vistas a construção de uma prática educativa humanizadora norteada pela psicologia histórico-cultural, na pedagogia histórico-crítica e no emprego do brinquedo e da brincadeira de papéis sociais na situação escolar. As autoras concluem que os professores carecem de uma visão de Educação Infantil como espaço promotor do desenvolvimento omnilateral da criança e de uma compreensão desta como sujeito social em construção, fruto das suas relações humanas, com tempos distintos para aprender e níveis diferentes de desenvolvimento. Destacam ainda a ausência do conhecimento, dentro da teoria de referência, que a brincadeira de papéis sociais é a atividade-guia para o processo de humanização das crianças pré-escolares.

Na sequência, “O protagonismo infantil por meio da resistência em Kamchatka (2003)", artigo de Keyla Andrea Santiago Oliveira e Pollyanna Rosa Ribeiro, tem-se a defesa do cinema e seus dispositivos estéticos como instrumento potente para revelar sutilezas que o cotidiano imediatista, muitas vezes não nos permite, dentre eles: o olhar da criança sobre o mundo e seus dramas inerentes à infância. Com esta premissa, as autoras empreendem a discussão sobre a leitura de mundo da criança em um contexto social vulnerável por meio do filme argentino Kamchatka (2003), apontando a vigorosidade da obra fílmica ao descortinar o impacto da penetração imperativa da barbárie da ditadura nos diversos meandros sociais, em especial, na vida infantil, e a criança potente enquanto ser de resistência.

Encerra o dossiê o texto de Juliana Silva Santiago, Luísa Lenhardt, José Ricardo Silva e Fabio Machado Pinto sob o título: "O voo livre como conteúdo da Educação Física na Educação Infantil: descobertas e desafios", que relata uma experiência de ensino de Educação Física na Educação Infantil que tematiza o voo livre (parapente e asa delta). Os autores destacam que a experiência de ensino proporcionou às crianças a capacidade de identificação e diferenciação entre asa delta e o parapente enquanto experimentavam situações de equilíbrio/desequilíbrio em lugares altos e baixos, construíam brinquedos, brincavam e estabeleciam contato com equipamentos reais. Por fim, salientam a importância da formação docente, o planejamento e ensino de práticas de aventura, assim como melhor conhecer os sujeitos deste processo.

Abre a sessão de artigos de fluxo contínuo o artigo intitulado "Metodologias ativas no ensino de Física: um panorama da pesquisa stricto sensu brasileira" de José Eugênio Brum da Rosa e Josefina Barrera Kalhil. Os autores expõem o estudo, de cunho exploratório, que teve como objetivo principal traçar um panorama das pesquisas stricto sensu realizadas no Brasil, abordando o uso de metodologias ativas no ensino de Física, no período compreendido entre 2009 e 2019. Para atingir tal objetivo analisam teses e dissertações disponíveis no acervo da Biblioteca Digital Brasileira de Teses e Dissertações - BDTD.

O texto a seguir: "O trabalho como categoria ontológica: uma análise a partir da obra cinematogrática 'Eu, Daniel Blake'”, de Luis Henrique Zago, Neiva Solange Silva, Allan Alberto Ferreira, Rodrigo Lima Nunes e Irineu Aliprando Tuim Viotto Filho, discute o trabalho como categoria essencial no processo ontológico humano utilizando como elemento figurativo do tema o filme "Eu, Daniel Blake", 
analisado à luz da teoria materialista histórico-dialética. Ao longo do texto abordam a relação entre os aspectos biológicos e culturais na formação e desenvolvimento humano; o caráter libertador desta atividade; as condições do trabalho alienado como ameaça produzida a essa liberdade e os impactos dessa forma de expropriação à subjetividade. Os autores consideram que o filme "Eu, Daniel Blake" demonstra, de modo artístico, a situação de conflito e sofrimento vivida por muitos trabalhadores na atualidade.

O último artigo que compõe esse número, "Aspectos do perfil de crianças que manifestam agressividade na Educação Infantil", de autoria de Gabrielly Doná e Andréia Cristiane Silva Wiezzel, apresenta um perfil das crianças que manifestam agressividade excessiva em sala de aula, levando em conta aspetos de sua subjetividade e do entorno. As autoras concluem que a maioria das crianças analisadas manifestam teimosia, possuem dificuldades em seguir regras, não gostam de ser contrariadas e não possuem limites, demonstrando, assim, baixa tolerância a frustração.

Finalizando, se faz importante reafirmar a necessidade de amplos debates, diversificadas reflexões sob as mais diferentes abordagens teórico-metodológicas e o constante empreendimento de esforços teóricos e práticos para a conquista de uma educação infantil de qualidade positiva para as crianças brasileiras. É nesse espírito que convidamos a todos para lerem os textos deste dossiê, aprofundarem seus conhecimentos, elaborar opiniões e se unir a luta pelos direitos da(s) criança(s) e sua(s) infância(s).

Desejamos a todos uma ótima leitura!

Profa. Dra. Sílvia Adriana Rodrigues Prof. Dr. José Ricardo Silva (Organizadores) 